Gülbin ÇETINKALE DEMIRKAN ${ }^{1}$

Zerrin SÖĞÜT2

İbrahim YOKAŞ3

1 Niğde Ömer Halisdemir Üniversitesi, Mimarlık Fakültesi, Peyzaj Mimarlığı Bölümü, 51240, Niğde / Türkiye

2 Çukurova Üniversitesi, Ziraat Fakültesi, Peyzaj Mimarlı̆ı Bölümü, 01250, Adana /Türkiye

${ }^{3}$ Muğla Sıtkı Koçman Üniversitesi, Ortaca Meslek Yüksekokulu, Bitkisel ve Hayvansal Üretim Bölümü, 48000, Muğla /Türkiye

sorumlu yazar: gulcetinkale@gmail.com

Anahtar Sözcükler:

Arıtma çamuru, bertaraf, Platanus

orientalis, yeniden kullanım

Key Words:

Sewage sludge, dispose, platanus orientalis, reuse

\section{Atık Su Arıtma Çamuru Uygulamalarının Platanus orientalis (Çınar) Türüne Etkileri*}

\author{
The Effects of Sewage Sludge Applications on Platanus \\ orientalis Species
}

*Bu çalışma ilk yazarın doktora tezinden hazırlanmıştır.

Alınış (Received): 05.06.2017Ｋabul tarihi (Accepted): 17.07.2017

\section{ÖZET}

Bu çalışmada Gökova-Akyaka Atık Su Arıtma Tesisinden temin edilen arıtma D çamurunun, Platanus orientalis L. (Çınar) türünde, toprağa serilerek kullanımının bitki gelişimi üzerine etkileri belirlenmiştir. Çalışmada 2 yıl boyunca arıtma çamuru 4 ayda bir ve her uygulamada $20 \mathrm{~kg} / \mathrm{m}^{2}$ miktarında verilmiştir. Deneme 3 tekerrürlü olacak şekilde tesadüf parselleri bölünen bölünmüş deneme desenine göre kurulmuştur. Deneme süresince bitkilerde bitki boyu, gövde çapı ve yaprak rengi kriterleri incelenmiştir. Denemenin birinci ve ikinci yılları sonunda da yapraklarda bazı bitki besin elementi ve ağır metal analizleri yapılmıştır. Araştırma sonucunda $P$. orientalis türünün artan arıtma çamuruna rahat tepki verdiği, uygulanan dozların herhangi bir toksik etkiye sebep olmadığı ve yılda 60 $\mathrm{kg} / \mathrm{m}^{2}$ miktarında kullanımının uygun olacağı belirlenmiştir.

\begin{abstract}
n this stıdy, the sewage sludge taken from Gökova-Akyaka Wastewater Treatment Plant was used as soil cover materail in Platanus orientalis L. the effect of this material on the plant growth was investigated. The study was established for two years and the cover material applicated once in four months as $20 \mathrm{~kg} / \mathrm{m}^{2}$ doses. Research was conducted as 3 replicates and according to random parcels split-split plot design. During the study plant height, body diameter and leaf color criterias were examined. At the end of the first and the second year of the study, some plant nutrient elements and heavy metals were analysed in the leaves. As result of the study $P$. orientalis species effected positively from sewage sludge and the application doses having any toxic affects. The most suitable dose per year is $60 \mathrm{~kg} / \mathrm{m}^{2}$.
\end{abstract}

\section{Gíiş}

Şehirleşme ve nüfusun giderek artması, gelişen sanayi ve teknoloji ile artan tüketim ihtiyacı sonucu ortaya çıkan atıklar çevre açısından önemli bir kirliliği de beraberinde getirmektedir. Sorunun çözülmesi amacıyla kullanılan pekçok yöntem de farklı sorunlar yaratmaktadır. Genelde gelişi güzel bir yerlere atılarak veya yakılarak yok edilmeye çalışılan atıklar çevre ve doğal kaynaklara geri dönüşü olmayan zararlar vermeye başlamıştır. Atıkların bilinçsiz bir şekilde yok edilmeye çalışılması yerine, kaynağında ayrıştıılarak, yeniden kullanımı mümkün olan atıkların farklı alanlarda değerlendirilmesiyle hem atık gideriminin sağlanmasında hem de ekonomik açıdan ülkelere katkıda bulunulmaktadır (Çetinkale Demirkan ve ark., 2014; Akat ve ark., 2013). Böylece işlevselliği yüksek işlenebilir atıklar değişik alanlarda kullanılarak faydalı ürünlere dönüştürülebilmektedir. Bu doğrultuda içeriğinde bitki için yarayışlı elementlerinde bulunduğu (Kabata-Pendias, 2011) arıtma tesislerinden son ürün olarak çıkan arıtma çamurlarının farklı alanlarda yeniden kullanımıyla çevrenin sürdürülebilirliği sağlanarak uygun şekilde bertaraf edilmesiyle, kirlilik etmeninin ortadan kaldırıması bu atık için çözüm niteliği taşımaktadır. Ancak, arıtma çamurları meydana geldiği atık suyun özelliklerine bağlı olarak içinde; organik bileşikler, hidrokarbonlar, metal tuzları, demir, 
bakır, alüminyum, civa, kadmiyum, arsenik, kobalt, kurşun, krom gibi ağır metaller, organik fosfor ve azot gibi maddeler ile çeşitli patojen mikroorganizmalar içerebilmektedir (Garcia-Gomez et al. 2002; Grigatti, 2007; Pathak et al. 2009; ). Bu nedenle besin zinciri yoluyla ulaşımının mümkün olmayacağı alanlarda, özellikle bitki yetiştiriciliğinde, toprak düzenleyici ve organik gübre kaynağı olarak kullanımları daha güvenilir olmaktadır (Katkat ve Aşık, 2010; Çetinkale Demirkan ve ark., 2013; Akat ve ark., 2015a). Ancak kullanılan ülkenin yönetmeliklerine uygunluğu belirlendikten sonra değerlendirilmesi ileride ortaya çıkacak sorunların da önüne geçecektir (Yıldız ve Değirmenci, 2014; Akat ve ark., 2015b). Bu doğrultuda kullanımlarıyla potansiyel risklerin söz konusu olmadığ bazı süs bitkisi türlerinde arıtma çamuru uygulamalarının tercih edilmeleri ile bu atıkların bertarafı konusunda bir çözüm noktası oluşturulabileceği düşünülmektedir.

Bu noktadan hareketle, Platanus orientalis L. (Çınar) türü, ülkemizde doğal bitki örtüsü içinde bulunması, peyzaj çalışmalarında yoğun bir şekilde kullanılması, yol ağaçlandırmalarında sıklıkla kullanılan bir tür olması sebebiyle tercih edilmiştir. "Gökova-Akyaka Atık Su
Arıtma Tesisi"nden alınan atık su arıtma çamurunun artan dozlardaki uygulamasının bu türde bitki gelişimi ile yaprakta bazı bitki besin elementi ve ağır metal etkilerinin ortaya konulması amaçlanmıştır.

\section{MATERYAL ve YÖNTEM}

Araştırma Mart 2012 - Haziran 2014 arasında, Ortaca Belediyesi Park Bahçeler Ünitesine ait 450 $\mathrm{m}^{2 \prime}$ lik açık alanda yürütülmüştür. Bitkisel materyal olarak, Gökova Orman Fidanlığı'ndan temin edilen üç yaşındaki Platanus orientalis L. (Çınar) fidanları kullanılmıştır. Platanus orientalis fidanları çıplak köklü olarak temin edilmiştir. Toplamda 96 adet fidan kullanılmıştır. Araştırma, tesadüf parselleri bölünen bölünmüş deneme desenine göre 3 tekerrürlü olacak şekilde kurulmuştur. Parsellerin oluşturulması sonrasında tesadüf parselleri deneme desenine göre, her parselde 8 bitki olacak şekilde dikimlerin yapılmasıyla denemeye başlanmıştır. Yılda üç kez uygulanan arıtma çamuru kontrol parselleri hariç her seferinde $20 \mathrm{~kg} / \mathrm{m}^{2}$ olacak şekilde toprak üzerine serpilmiştir. Uygulama dozları ve uygulama tarihleri Çizelge 1'de verilmiştir.

Çizelge 1. Arıtma Çamuru Uygulama Tarihleri ve Miktarları Table 1. Applications and Dates of Sewage Sludge

\begin{tabular}{|c|c|}
\hline Uygulamalar & Uygulama Tarihleri \\
\hline Kontrol: Bitkinin bulunduğu arıtma çamuru uygulanmamış parseller. & - \\
\hline D1: Yılda 1 kez arıtma çamuru uygulaması $\left(20 \mathrm{~kg} / \mathrm{m}^{2}\right)$ & $\begin{array}{l}\text { 1.yıl: } 18.06 .2012 \\
\text { 2.yıl: } 18.06 .2013\end{array}$ \\
\hline D2: Yılda 2 kez arıtma çamuru uygulaması $\left(40 \mathrm{~kg} / \mathrm{m}^{2}\right)$ & $\begin{array}{l}\text { 1.yıl: } 18.06 .2012,18.10 .2012 \\
\text { 2.yıl: } 18.06 .2013,18.10 .2013\end{array}$ \\
\hline D3: Yılda 3 kez arıtma çamuru uygulaması $\left(60 \mathrm{~kg} / \mathrm{m}^{2}\right)$ & $\begin{array}{l}\text { 1.yyl: } 18.06 .2012,18.10 .2012,18.02 .2013 \\
\text { 2.yıl: } 18.06 .2013,18.10 .2013,18.02 .2014\end{array}$ \\
\hline
\end{tabular}

Araştırmada kullanılan atık su arıtma çamuru "Gökova-Akyaka Atık Su Arıtma Tesisi"nden temin edilmiştir. Çalışma süresince tesisten alınan arıtma çamuru ile deneme alanındaki toprağın bazı fiziksel ve kimyasal özellikleri yapılan analizlerle belirlenmiştir (Çizelge 2).

Çizelge 2. Arıtma çamurları ve toprağa ilişkin bazı fiziksel ve kimyasal özellikler Table 2. Some physical and chemical properties of sewage sludge and soil

\begin{tabular}{lccccc}
\hline \multirow{2}{*}{ Yapılan Analizler } & \multirow{2}{*}{ Birim } & \multicolumn{2}{c}{ Toprak } & \multirow{2}{*}{ Arıtma Çamuru } & \multirow{2}{*}{ Sinır Değer* } \\
\cline { 3 - 4 } & & $\mathbf{0 - 3 0} \mathbf{~ c m}$ & $\mathbf{3 0 - 5 0} \mathbf{~ c m}$ & & \\
\hline pH & & 8.14 & 7.96 & 7.34 & - \\
EC & $(\mu \mathrm{S} / \mathrm{cm})$ & 53.4 & 67.2 & 1194 & - \\
Organik Madde & $(\%)$ & 6.81 & 6.22 & 74.99 & - \\
C/N Oranı & & - & - & 11.60 & - \\
Toplam Azot & $(\mathrm{mg} / \mathrm{g})$ & 0.84 & 0.62 & 3.750 & - \\
Toplam Fosfor & $(\mathrm{mg} / \mathrm{kg})$ & 1518 & 653 & 3715 & - \\
Toplam Potasyum & $(\mathrm{mg} / \mathrm{kg})$ & 629.7 & 473 & 1081 & - \\
Toplam Alüminyum & $(\mathrm{mg} / \mathrm{kg})$ & - & - & 2575 & - \\
Toplam Demir & $(\mathrm{mg} / \mathrm{kg})$ & - & - & 5252 & - \\
Toplam Bakır & $(\mathrm{mg} / \mathrm{kg})$ & - & - & 15.81 & 1000 \\
Toplam Kadmiyum & $(\mathrm{mg} / \mathrm{kg})$ & - & - & 0.77 & 10 \\
Toplam Kurşun & $(\mathrm{mg} / \mathrm{kg})$ & - & - & 9.33 & 750 \\
Toplam Nikel & $(\mathrm{mg} / \mathrm{kg})$ & - & - & 41.04 & 300 \\
\hline
\end{tabular}

*27661 Sayılı Evsel ve Kentsel Arıtma Çamurlarının Toprakta Kullanıımasına Dair Yönetmelik 
Çamur her bir parseldeki toprak üzerine $2 \mathrm{~cm}$ kalınlıkta olacak şekilde serilerek uygulanmıştır. Bir kerede uygulanan arıtma çamuru $20 \mathrm{~kg} / \mathrm{m}^{2}$ olmuştur. Illk çamur serilmesi ile birlikte her ay ölçüm ve gözlem yoluyla alandaki bitkilerde bitki boyu, gövde çapı ve renk (Skala Değeri: 1: Sarımsı Yeşil, 2: Yeşil, 3: Koyu Yeşil) kriterlerine ait veriler toplanmıştır. Veriler, her yıl kendi içerisinde ve denemenin sonlanmasıyla iki yılın birlikte değerlendirilmesiyle elde edilmiştir. Bitki yapraklarından da her yıl sonunda örnekler alınarak toplam $\mathrm{N}(\%), \mathrm{Fe}$ (ppm), Cu (ppm), Zn (ppm), Mn (ppm), Ni (ppm), Pb (ppm) ve $\mathrm{Cd}(\mathrm{ppm})$ değerleri Ege Üniversitesi Ziraat Fakültesi, Toprak Bilimi ve Bitki Besleme Bölümü"ne ait laboratuvarda analiz edilmiştir. Laboratuvarda bitki örneklerinde; $N$ modifiye edilmiş Kjeldahl metoduna göre; toplam $\mathrm{Fe}, \mathrm{Cu}, \mathrm{Zn}, \mathrm{Mn}$ miktarları yaş yakma yöntemi (4 kıım $\mathrm{HNO}_{3}+1$ kısım $\mathrm{HClO}_{4}$ ) ile elde edilen ekstraktın; toplam $\mathrm{Cd}$, $\mathrm{Ni}$ ve $\mathrm{Pb}$ analizlerinde ise $500-550^{\circ} \mathrm{C}$ 'de kül haline getirilen bitki örneklerinin $2 \mathrm{~N} \mathrm{HCl}$ ile elde edilen ekstraktın atomik absorbsiyon spektrofotometresinde okunması sonucuyla belirlenmiştir (Slawin, 1955; Isaac and Kerber, 1969; Kacar, 1972; Kacar ve İnal 2008).

Araştırmanın tüm aşamalarında elde edilen sayısal veriler istatistiksel olarak SPSS 15.0 paket programı kullanılarak yapılmış; önem dereceleri "One Way Anova"da "Duncan" testine göre belirlenmiştir.

\section{ARAŞTIRMA BULGULARI ve TARTIŞMA}

"Gökova-Akyaka Atık Su Arıtma Tesisi" arıtma çamurlarının Platanus orientalis türünde etkilerinin araştıııldığı çalışmada bitki boyu, gövde çapı, yaprak rengi kriterlerine ait değerler ile bitki yapraklarında bazı besin elementi ve ağır metal içeriklerinin sonuçları Çizelge 3, 4, 5 ve 6'da verilmektedir.

Çizelge 3. Arıtma Çamurunun Bitki Boyu Artış Ortalamalarına Etkileri

Table 3. Effects of sewage sludge to plant height increase average

\begin{tabular}{llllll}
\hline \multirow{2}{*}{ Tarihler } & \multicolumn{5}{c}{ Bitki Boyundaki Artışların Ortalamaları (cm) } \\
\cline { 2 - 6 } & Kontrol & Doz 1 & Doz 2 & Doz 3 & Önemlilik \\
\hline Temmuz & 3.68 & 5.57 & 5.17 & 5.27 & Öd \\
Ağustos & $4.22^{\mathrm{b}}$ & $5.78^{\mathrm{ab}}$ & $7.13^{\mathrm{ab}}$ & $8.36^{\mathrm{a}}$ & $0.034^{*}$ \\
Eylül & 5.36 & 5.14 & 5.91 & 6.72 & Öd \\
Ekim & 6.77 & 7.71 & 8.65 & 13.36 & Öd \\
Kasım & 2.50 & 1.42 & 2.04 & 2.72 & Öd \\
Mart & 3.86 & 3.00 & 7.21 & 7.31 & Öd \\
Nisan & 8.77 & 10.78 & 10.13 & 11.40 & Öd \\
Mayıs & $13.63^{\mathrm{b}}$ & $17.00^{\mathrm{ab}}$ & $19.82^{\mathrm{ab}}$ & $23.50^{\mathrm{a}}$ & $0.031^{*}$ \\
Haziran & $14.13^{\mathrm{b}}$ & $23.71^{\mathrm{a}}$ & $22.13^{\mathrm{a}}$ & $29.77^{\mathrm{a}}$ & $0.001^{* *}$ \\
\hline I. Yıl Boy Artışı $(\mathrm{cm})$ & $\mathbf{6 . 9 9}$ & $\mathbf{8 . 9 0}$ & $\mathbf{9 . 7 9}$ & $\mathbf{1 2 . 0 4}$ & - \\
I. Yıl Boy Uzaması $(\mathrm{cm})$ & $\mathbf{6 0 . 3 8}$ & $\mathbf{9 5 . 7 5}$ & $\mathbf{8 1 . 7 1}$ & $\mathbf{1 0 1 . 1 7}$ & - \\
\hline Temmuz & $16.81^{\mathrm{b}}$ & $23.42^{\mathrm{ab}}$ & $26.65^{\mathrm{a}}$ & $24.22^{\mathrm{ab}}$ & $0.027^{*}$ \\
Ağustos & 20.45 & 20.85 & 29.56 & 29.00 & Öd \\
Eylül & $18.36^{\mathrm{b}}$ & $25.78^{\mathrm{a}}$ & $18.78^{\mathrm{b}}$ & $22.31^{\mathrm{ab}}$ & $0.035^{*}$ \\
Ekim & 14.59 & 18.21 & 17.82 & 18.40 & Öd \\
Kasım & 6.22 & 6.71 & 4.56 & 5.27 & Öd \\
Mart & 25.00 & 29.07 & 24.47 & 27.04 & Öd \\
\hline Nisan & 23.22 & 21.57 & 24.39 & 26.90 & Öd \\
\hline Mayıs & $37.72^{\mathrm{ab}}$ & $29.42^{\mathrm{b}}$ & $42.04^{\mathrm{a}}$ & $43.50^{\mathrm{a}}$ & $0.042^{*}$ \\
Haziran & $42.86^{\mathrm{a}}$ & $24.07^{\mathrm{b}}$ & $37.95^{\mathrm{ab}}$ & $49.31^{\mathrm{a}}$ & $0.015^{*}$ \\
\hline II.Yıl Boy Artışı I (cm) & $\mathbf{2 2 . 7 4}$ & $\mathbf{2 2 . 1 2}$ & $\mathbf{2 5 . 1 3}$ & $\mathbf{2 7 . 3 2}$ & - \\
II.Yıl Boy Uzaması $(\mathrm{cm})$ & $\mathbf{1 8 3 . 1 7}$ & $\mathbf{1 9 8 . 5 0}$ & $\mathbf{2 0 5 . 3 8}$ & $\mathbf{2 0 5 . 6 7}$ & - \\
\hline Iki Yıllık Boy Artışı $(\mathrm{cm})$ & $\mathbf{1 4 . 8 6}$ & $\mathbf{1 5 . 5 1}$ & $\mathbf{1 7 . 4 6}$ & $\mathbf{1 9 . 6 8}$ & - \\
\hline Iki Yıllık Boy Uzaması $(\mathrm{cm})$ & $\mathbf{2 5 7 . 7 2}$ & $\mathbf{3 1 9 . 0 4}$ & $\mathbf{3 1 6 . 0 0}$ & $\mathbf{3 2 8 . 3 4}$ & - \\
\hline
\end{tabular}

Doz1: $20 \mathrm{~kg} / \mathrm{m}^{2}$ yıl Doz2: 40 kg/m²yıl Doz3: $60 \mathrm{~kg} / \mathrm{m}^{2} \mathrm{yll}$

Çizelge 3'deki önemliliğe ait değerler incelendiğinde artışlar arasında I. yıl Ağustos ve Mayıs aylarında istatistiksel olarak $p<0.05$, Haziran ayında ise $p<0.01$; Il. yıl ise Temmuz, Eylül, Mayıs ve Haziran aylarında $p<0.05$ önem düzeyinde farklılıklar olduğu belirlenmiştir.
Platanus orientalis türünde I. yıl artan dozda arıtma çamuru uygulamasının tamamlanmasıyla, bitki boyundaki en fazla artış ortalaması $12.04 \mathrm{~cm}$ ile en yüksek doz olan doz $3\left(60 \mathrm{~kg} / \mathrm{m}^{2}\right.$ yıl $)$ uygulamasından elde edilirken artan doz uygulamasına paralel olarak boy artışı olduğu, en 
düşük değerin kontrol ortamından elde edildiği belirlenmiştir. I. yıl $100 \mathrm{~cm}$ 'nin üzerinde boy uzaması olduğu tespit edilmiştir. Il. yılın tamamlanmasıyla en fazla boy artışının I. yıl ile benzer şekilde $27.32 \mathrm{~cm}$ ile doz $3\left(60 \mathrm{~kg} / \mathrm{m}^{2}\right.$ yıl) uygulamasından elde edildiği doz $1\left(20 \mathrm{~kg} / \mathrm{m}^{2}\right.$ yıl) uygulamasının kontrol ile yakın değerlerde olduğu ancak kontrolün gerisinde kaldığı saptanmıştır. II. yılda bitkilerde arıtma çamurunun etkisiyle $200 \mathrm{~cm}$ 'nin üzerinde boy uzaması olduğu belirlenmiştir. Denemenin sonlanması ile, en fazla boy artışının $19.68 \mathrm{~cm}$ ile doz $3\left(60 \mathrm{~kg} / \mathrm{m}^{2}\right.$ yıl) uygulamasından elde edildiği, kontrolün artan dozlarda uygulanan arıtma çamuru dozlarının gerisinde kaldığı tespit edilmiştir. Denemenin sonunda arıtma çamuru uygulanan bitkilerde 300 cm'den fazla boy uzaması olduğu saptanmıştır.

İki yıllık değerlerin incelenmesi sonucunda; I. yılda kontrol ile doz 1 uygulamasından benzer ve en düşük değerler elde edilmesine rağmen II. yılda artan doz uygulamasına paralel olarak arıtma çamurunun boy artışını olumlu etkilediği, kontrole göre daha fazla boy artışına sebep olduğu, doz 3'ün bitki boyunu en fazla arttırdığı tespit edilmiştir. Platanus orientalis türünün bitki boyu artışı açısından arıtma çamuru uygulamalarından olumlu etkilendiği belirlenmiştir. Hernandez-Apaolaza et al., (2005)'in Cupressus sempervirens ve C. arizonica türlerinin yetiştirilmesinde kullandıkları \%30 arıtma çamurunun bitki gelişmesini olumlu etkilediği, Manas and Castro (2008)'in Pinus pinaster türünde 7 farklı ortam içerisinde en iyi gelişmeyi arıtma çamurundan elde ettiği bulgularla, Akat ve ark. (2015b)'in Limonium sinuatum 'Compindi White' çeşidini kullandıkları çalışmalarında en yüksek çiçek sapı uzunluğunun en yüksek doz olan \%75 arıtma çamuru ortamından elde ettikleri bulguları ile denemeden elde edilen bulgular paralellik göstermektedir.

Çizelge 4'de artan atık su arıtma çamuru uygulamalarının gövde çapı artışına etkileri verilmektedir.

Çizelge 4. Arıtma çamurunun gövde çapı artış ortalamalarına etkileri Table 4. Effects of sewage sludge to body diameter increase average

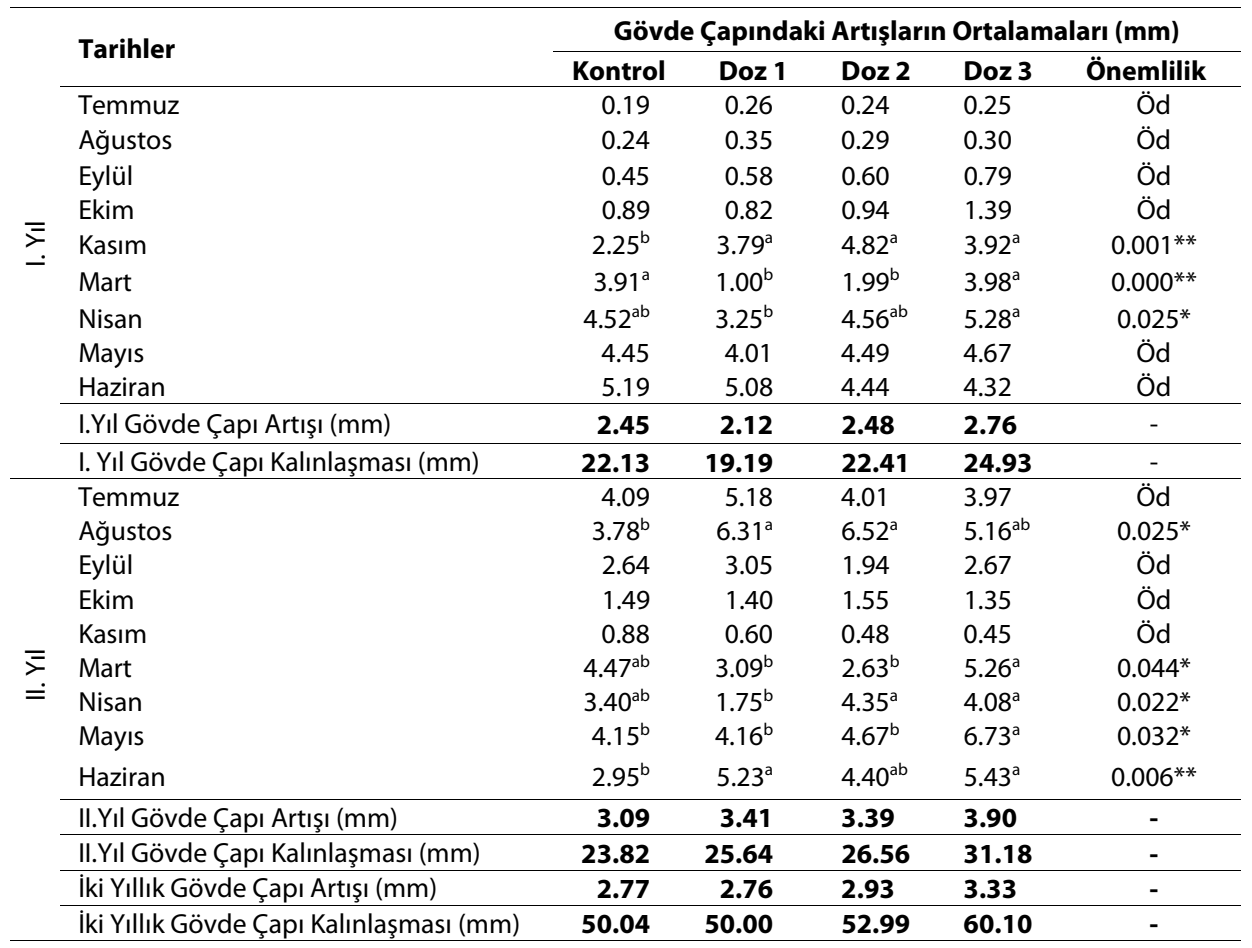

Doz1: 20 kg/m² yıl Doz2: 40 kg/m²yıl Doz3: 60 kg/m² yıl

I. yıla ait artışların istatistiksel analizi değerlendirildiğinde; Kasım ve Mart aylarında $p<0.01$, Nisan ayında ise $p<0.05$ önem düzeyinde farklılıkların olduğu, II. yıl ise Ağustos, Mart, Nisan ve Mayıs aylarında $p<0.05$, Haziran ayında ise $p<0.01$ önem düzeyinde farklılıkların olduğu belirlenmiştir. I. yıl sonunda gövde çapında en fazla artışın $2.76 \mathrm{~mm}$ ile en yüksek doz uygulaması olan doz $3\left(60 \mathrm{~kg} / \mathrm{m}^{2}\right.$ yıl) uygulamasından 
elde edildiği, doz 1 (20 kg/m² yıl) uygulamasının kontrolün gerisinde kaldığı tespit edilmiştir. Bir yıl sonunda en kalın gövde çapına sahip olan doz 3 (60 $\mathrm{kg} / \mathrm{m}^{2}$ yıl) bitkilerinde yaklaşık $25 \mathrm{~mm}$ kalınlaşma olduğu belirlenmiştir. I. yıl ilk uygulama olan doz $1\left(20 \mathrm{~kg} / \mathrm{m}^{2}\right.$ yıl) uygulamasından bitkinin negatif etkilendiği ancak uygulamanın artmasıyla bu durumun değiştiği tespit edilmiştir. II. yılın tamamlanmasıyla en yüksek gövde çapı kalınlaşmasına $3.90 \mathrm{~mm}$ ile doz $3\left(60 \mathrm{~kg} / \mathrm{m}^{2}\right.$ yıl) uygulaması ile ulaşıldığı, kontrolün arıtma çamuru uygulamalarının gerisinde kaldığı belirlenmiştir. Arıtma çamurunun en yüksek dozu ile 2. yılda 30 mm'den fazla gövde çapı kalınlaşması sağlandığı tespit edilmiştir. İki yılın tamamlanmasıyla en yüksek değerlere $3.33 \mathrm{~mm}$ ile doz $3\left(60 \mathrm{~kg} / \mathrm{m}^{2}\right.$ yıl) uygulamasıyla ulaşıldığı, kontrol ile doz $1\left(20 \mathrm{~kg} / \mathrm{m}^{2}\right.$ yıl) arasında rakamsal bir fark olmadığı belirlenmiştir. En yüksek arıtma çamuru dozu uygulaması ile deneme sonunda $P$. orientalis türünde $60 \mathrm{~mm}$ kalınlaşma olduğu saptanmıştır. Denemenin sonlanmasıyla elde edilen veriler değerlendirildiğinde; arıtma çamuru uygulamalarının gövde çapı açısından kontrole göre daha fazla kalınlaşmaya sebep olduğu ve en fazla kalınlaşmanın doz $3\left(60 \mathrm{~kg} / \mathrm{m}^{2}\right.$ yıl)'den elde edildiği, doz 1 (20 kg/m² yıl) uygulamasından kontrole eşdeğer sonuçların alındığı ancak artan dozların gövde çapını etkili şekilde arttırdığı tespit edilmiştir. Tüfekçi ve ark. (2008) tarafindan Eucalyptus camaldulensis, Eucalyptus grandis ve Pinus brutia türlerinde gelişmenin önemli derece arttığı, Ostos et al. (2008)'nın Pistacia lentiscus türünde arıtma çamurunun bitki gelişimini olumlu etkilediği bulguları ile denemeden elde edilen bulguların paralel olduğu tespit edilmiştir.

Çizelge 5'de artan miktarda arıtma çamuru uygulamasının yaprak rengine etkileri verilmektedir.

\begin{tabular}{|c|c|c|c|c|c|}
\hline \multirow{13}{*}{$\bar{\Sigma}$} & \multirow{2}{*}{ Tarih } & \multicolumn{4}{|c|}{ Renk Değerleri (1: Açık Yeşil, 2: Yeşil, 3: Koyu Yeşil) } \\
\hline & & Kontrol & Doz 1 & Doz 2 & Doz 3 \\
\hline & Haziran & 1.75 & 1.68 & 1.42 & 1.68 \\
\hline & Temmuz & 1.95 & 2.00 & 2.38 & 2.15 \\
\hline & Ağustos & 2.00 & 2.68 & 2.38 & 2.31 \\
\hline & Eylül & 2.00 & 3.00 & 3.00 & 3.00 \\
\hline & Ekim & 2.00 & 1.73 & 1.71 & 2.68 \\
\hline & Kasım & 1.37 & 1.52 & 1.57 & 1.42 \\
\hline & Mart & 2.00 & 2.31 & 2.90 & 2.94 \\
\hline & Nisan & 2.33 & 2.15 & 2.61 & 2.78 \\
\hline & Mayıs & 2.12 & 2.84 & 3.00 & 2.94 \\
\hline & Haziran & 2.00 & 2.00 & 2.57 & 2.36 \\
\hline & I. Yıl Renk Ortalamaları & 1.95 & 2.19 & 2.35 & 2.42 \\
\hline \multirow{10}{*}{$\stackrel{\bar{\Sigma}}{=}$} & Temmuz & 2.00 & 2.26 & 2.38 & 2.68 \\
\hline & Ağustos & 1.83 & 2.68 & 2.33 & 2.89 \\
\hline & Eylül & 1.70 & 2.42 & 2.42 & 2.68 \\
\hline & Ekim & 1.00 & 1.68 & 1.38 & 1.89 \\
\hline & Kasım & 1.00 & 1.42 & 1.47 & 1.47 \\
\hline & Mart & 2.00 & 2.00 & 2.00 & 2.00 \\
\hline & Nisan & 2.00 & 2.00 & 2.42 & 2.31 \\
\hline & Mayıs & 2.00 & 2.42 & 2.57 & 2.73 \\
\hline & Haziran & 2.00 & 2.63 & 2.76 & 2.84 \\
\hline & II. Yıl Renk Ortalamaları & 1.72 & 2.16 & 2.19 & 2.38 \\
\hline \multicolumn{2}{|c|}{ Deneme Sonu Renk Ortalamaları } & 1.83 & 2.17 & 2.27 & 2.40 \\
\hline
\end{tabular}

Doz1: $20 \mathrm{~kg} / \mathrm{m}^{2}$ yıl Doz2: $40 \mathrm{~kg} / \mathrm{m}^{2}$ yıl Doz3: $60 \mathrm{~kg} / \mathrm{m}^{2} \mathrm{yll}$

Çizelge incelendiğinde Ağustos ayından itibaren arıtma çamuru uygulamaları ile yaprak rengindeki değişikliklerin başladığı görülmektedir. I. yıl sonunda artan çamur dozuna paralel olarak yaprak rengi kontrole göre koyulaşmış ve en koyu renk en yüksek doz olan doz $3\left(60 \mathrm{~kg} / \mathrm{m}^{2}\right.$ yıl) uygulamasından elde edilmiştir. II. yıl sonunda da I. yıl ile benzer sonuçların elde edildiği ve artan arıtma çamur dozlarına paralel olarak rengin koyulaştığı, en koyu rengin doz $3\left(60 \mathrm{~kg} / \mathrm{m}^{2}\right.$ yıl) uygulaması ile sağlandığı belirlenmiştir. Denemenin sonlandırılmasıyla artan arıtma çamuru dozlarının renge etkisi, özellikle doz $3\left(60 \mathrm{~kg} / \mathrm{m}^{2}\right.$ yıl $)$ uygulamasında kontrole göre daha yoğun görülmektedir. Arıtma çamuru uygulamalarının, $P$. orientalis türünde kontrole göre rengin koyulaşmasına ve çekiciliğinin artmasına sebep olduğu tespit edilmiştir. Arıtma çamuru uygulamalarının kontrol grubuna göre yaprak renklerinde koyulaşmaya neden olması bulgusu, Çelebi 
ve ark. (2010) ile Çelebi ve ark. (2011) tarafından da, bazı çim türlerinde kontrole göre artıma çamurunun rengi koyulaştırdığı bulgusu ile uyum içindedir.
Çizelge 6'da denemenin I. ve II. yıl sonunda yapraklarda yapılan toplam $\mathrm{N}, \mathrm{Fe}, \mathrm{Cu}, \mathrm{Zn}, \mathrm{Mn}, \mathrm{Ni}, \mathrm{Pb}$ ve $\mathrm{Cd}$ değerleri verilmektedir.

Çizelge 6. Yapraklarda Bazı Parametreler Üzerine Arıtma Çamuru Uygulamalarının Etkisi

Table 6. Effect of sewage sludge applications on some parameters in leaf

\begin{tabular}{|c|c|c|c|c|c|c|c|c|}
\hline Parametre & YıI* & Kontrol & Doz 1 & Doz 2 & Doz 3 & Önemlilik & Normal Değer* * & Toksik Değer** \\
\hline \multirow{2}{*}{ Toplam N (\%) } & $\mathbf{I}$ & $2.06^{c}$ & $2.27^{\mathrm{bc}}$ & $2.49^{\mathrm{ab}}$ & $2.63^{\mathrm{a}}$ & $0.004^{* *}$ & \multirow{2}{*}{-} & \multirow{2}{*}{ - } \\
\hline & II & $1.93^{c}$ & $2.13^{b}$ & $2.25^{\mathrm{ab}}$ & $2.38^{\mathrm{a}}$ & $0.002^{* *}$ & & \\
\hline \multirow{2}{*}{$\mathrm{Fe}(\mathrm{ppm})$} & $I$ & 67.75 & 111.41 & 92.16 & 127.75 & Öd & \multirow{2}{*}{ - } & \multirow[b]{2}{*}{ - } \\
\hline & II & $248.35^{b}$ & $306.30^{\mathrm{a}}$ & $264.55^{\mathrm{ab}}$ & $219.65^{b}$ & $0.013^{*}$ & & \\
\hline \multirow{2}{*}{$\mathrm{Cu}(\mathrm{ppm})$} & I & 5.53 & 5.24 & 6.69 & 5.52 & Öd & \multirow{2}{*}{$\begin{array}{c}5-30 \\
(\mathrm{ppm})\end{array}$} & \multirow{2}{*}{$\begin{array}{c}20-100 \\
(\mathrm{ppm})\end{array}$} \\
\hline & II & $4.50^{\mathrm{d}}$ & $7.90^{\mathrm{a}}$ & $5.50^{c}$ & $6.00^{\mathrm{b}}$ & $0.000^{* *}$ & & \\
\hline \multirow{2}{*}{ Zn (ppm) } & 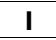 & 16.83 & 22.44 & 25.62 & 23.45 & Öd & \multirow{2}{*}{$\begin{array}{c}27-150 \\
(\mathrm{ppm})\end{array}$} & \multirow{2}{*}{$\begin{array}{c}100-400 \\
(\mathrm{ppm})\end{array}$} \\
\hline & II & $11.97^{c}$ & $15.05^{\mathrm{a}}$ & $15.49^{\mathrm{a}}$ & $13.55^{b}$ & $0.000^{* *}$ & & \\
\hline \multirow{2}{*}{ Mn (ppm) } & $I$ & 61.63 & 67.15 & 54.44 & 61.43 & Öd & \multirow{2}{*}{$30-300(\mathrm{ppm})$} & \multirow{2}{*}{$\begin{array}{c}400-1000 \\
(\mathrm{ppm})\end{array}$} \\
\hline & II & $51.45^{c}$ & $55.05^{c}$ & $73.60^{b}$ & $101.30^{\mathrm{a}}$ & $0.000^{* *}$ & & \\
\hline \multirow{2}{*}{$\mathrm{Ni}(\mathrm{ppm})$} & I & 5.34 & 5.73 & 6.23 & 6.92 & Öd & \multirow{2}{*}{$\begin{array}{c}0.1-5 \\
(\mathrm{ppm})\end{array}$} & \multirow{2}{*}{$\begin{array}{l}10-100 \\
(\mathrm{ppm})\end{array}$} \\
\hline & II & $15.35^{c}$ & $17.95^{\mathrm{b}}$ & $20.80^{a}$ & $21.80^{\mathrm{a}}$ & $0.000^{* *}$ & & \\
\hline \multirow[b]{2}{*}{$\mathrm{Pb}$ (ppm) } & $\mathbf{I}$ & iz & iz & iz & iz & - & \multirow{2}{*}{$\begin{array}{c}5-10 \\
(\mathrm{ppm})\end{array}$} & \multirow{2}{*}{$\begin{array}{l}30-300 \\
(\mathrm{ppm})\end{array}$} \\
\hline & II & $37.50^{c}$ & $42.50^{b}$ & $46.50^{a}$ & $45.00^{\mathrm{ab}}$ & $0.001^{* *}$ & & \\
\hline \multirow{3}{*}{$\mathrm{Cd}$ (ppm) } & $\mathbf{I}$ & iz & iz & iz & iz & - & \multirow{3}{*}{$\begin{array}{c}0.05-0.2 \\
(p p m)\end{array}$} & \multirow{3}{*}{$\begin{array}{c}5-30 \\
(\mathrm{ppm})\end{array}$} \\
\hline & II & İz & İz & $\mathrm{izz}$ & ìz & - & & \\
\hline & II & $\grave{z} z$ & ìz & iz & $\dot{\mathrm{I} z}$ & - & & \\
\hline
\end{tabular}

Öd: Önemli Değil * $0.05,{ }^{* *} 0.01$ önem düzeyini, harfler de aynı grup içerisinde bulunan değerleri göstermektedir. Doz 1: $20 \mathrm{~kg} / \mathrm{m}^{2}$ yıl Doz 2: 40 $\mathrm{kg} / \mathrm{m}^{2}$ yll Doz 3: $60 \mathrm{~kg} / \mathrm{m}^{2}$ yll

**Kabata-Pendias, 2011

I. yıl yaprak analizleri incelendiğinde Toplam N değerlerinin arıtma çamuru uygulaması sonucunda beklendiği gibi kontrole göre artışa sebep olduğu belirlenmiştir. İstatistiksel olarak incelendiğinde, p $<0.01$ önem düzeyinde farklılıkların bulunduğu tespit edilmiştir. Arıtma çamuru $\mathrm{N}$ miktarınca zengin bir atık olması bitki yapraklarındaki $N$ miktarının yüksek çıkmasıyla bağlantılı değerlendirilmiştir. $\mathrm{Pb}$ ve $\mathrm{Cd}$ 'a ait değerlerin eser miktarda olduğu görülmektedir. Ancak ağır metal miktarının kontrole göre arıtma çamuru uygulamalarında çoğunlukla daha yüksek olduğu tespit edilmiştir. Ağır metaller açısından ise değerler arasında istatistiki anlamda herhangi bir farklılık bulunmadığı belirlenmiştir. Bose et al. (2008) tarafından, arıtma çamuru miktarının artmasıyla bitkilerde ağır metal konsantrasyonlarının arttığı bulgusu ile denemeden elde edilen bulgunun paralel, Li et al. (2008)'in çalışmasından elde edilen Ni ve Zn'nin bitkide azalan miktarlarda olduğu bulgusu ile zit olduğu tespit edilmiştir.

II. yıl yaprak analizlerinin değerlendirilmesi sonucunda, istatistiki anlamda uygulamalar arasında $\mathrm{N}$, $\mathrm{Cu}, \mathrm{Zn}, \mathrm{Mn}, \mathrm{Ni}, \mathrm{Pb}$ ve Co miktarlarında $\mathrm{p}<0.01$, Fe ise $p<0.05$ önem düzeyinde farklılıklar olduğu belirlenmiştir. $N$, I. yılla benzer şekilde arıtma çamuru dozunun artmasına paralel olarak kontrole göre daha yüksek miktarlara ulaşmıştır. $\mathrm{Cd}$ değerinin eser miktarda olduğu da görülmektedir. Çimrin ve ark. (2000) tarafından $\mathrm{Zn}$ ve Fe düzeyinin önemli seviyede arttığı, Fuentes et al. (2007) ve Bramryd (2013)'ın çalışmalarındaki $\mathrm{Cu}, \mathrm{Ni}$ ve $\mathrm{Zn}$ miktarlarında sınırlı bir artış olduğu, Bai et al. (2014) tarafından $\mathrm{Mn}, \mathrm{Cu}, \mathrm{Zn}, \mathrm{Ni}$ ve $\mathrm{Pb}$ miktarında artış olduğu bulgusu ile denemeden elde edilen bulgular arasında paralellik olduğu tespit edilmiştir.

\section{SONUÇ ve ÖNERILER}

Atık su arıtma tesislerinden her geçen gün artan miktarlarda son ürün olarak çıkan arıtma çamurlarının bertarafı önem kazanmıştır. Çevre açısından yaratacağı sorunları önlemek ve alternatif bir çözüm noktası olması adına süs bitkileri sektöründe bir bertaraf sahası olarak yeşil alanlarda kullanılmasıyla arıtma çamurlarının bertarafının sağlanması üzerinde önemle durulan bir konudur.

Muğla ili Gökova-Akyaka atık su arıtma tesisinden temin edilen arıtma çamurunun Platanus orientalis türüne artan dozlarda uygulanması, incelenen kriterlerden bitki boyunda kontrol bitkilerine göre daha uzun boylu bitkilerin yetişmesini sağlamıştır. Özellikle $60 \mathrm{~kg} / \mathrm{m}^{2}$ yıl uygulama dozu en uzun boylu Platanus orientalis fidanlarını oluşturmuştur.

Gövde çapı kriteri değerlendirildiğinde $60 \mathrm{~kg} / \mathrm{m}^{2}$ yı uygulama dozu, kontrol ve diğer arıtma çamuru 
uygulamalarına göre daha etkili olarak tespit edilmiştir. Arıtma çamuru uygulamaları kontrole göre daha geniş gövde çapları oluşumunu sağlamıştır. Buna göre arıtma çamuru uygulamaları daha kalın gövde çapına sahip bireylerin oluşumunu teşvik etmektedir. Yaprak rengi ne ait veriler değerlendirildiğinde, Platanus orientalis türünde arıtma çamuru uygulamalarının tamamı yaprak renginde kontrol bitkilerine göre daha koyu yeşil yaprak oluşumuna neden olmuştur. İki yılın sonunda $60 \mathrm{~kg} / \mathrm{m}^{2}$ yıl düzeyinde arıtma çamuru uygulaması en koyu yeşil yaprak oluşumunu sağlamıştır. Buna göre arıtma çamuru uygulaması koyu yeşil yapraklı fidanların üretimini sağlamaktadır.

Platanus orientalis yapraklarında arıtma çamuru uygulamalarının tamamı kontrole göre toplam $\mathrm{N}$ ve Fe'in artmasına neden olmuştur. $\mathrm{Cu}$ ve $\mathrm{Mn}$ bitkide bulunan normal değerler aralığı içinde, $\mathrm{Cd}$ iz miktarlarda, Zn kontrol parselleri de dahil olmak üzere normal değerler aralığının altındadır.

Bitkide en fazla birikim Ni ve Pb'da görülmüştür. Ni ilk yıl kontrol ve $20 \mathrm{~kg} / \mathrm{m}^{2}$ yıl dozunda normal değerler aralığı içinde, $40 \mathrm{~kg} / \mathrm{m}^{2}$ yıl ve $60 \mathrm{~kg} / \mathrm{m}^{2}$ yıl dozlarında ise bu değerleri aşmış, ancak toksik değerler aralığına ulaşmamıştır. İkinci yıl kontrol dahil tüm parsellerdeki bitki yapraklarında toksik değerler aralığı alt sınırını aşmıştır. Pb ilk yıl eser miktarlarda, ikinci yıl kontrol de dahil olmak üzere toksik değerler aralığı alt sınırını aşan miktarlardadır. Buna göre arıtma çamuru

\section{KAYNAKLAR}

Akat, H., G. Çetinkale Demirkan, Ö. Akat ve İ. Yokaş, 2015a. 'Limonium sinuatum' yetiștiriciliginde farklı ortamlara ilave edilen atık su arıtma çamurunun süs bitkisi yetiștirme materyali karışımı olarak kullanımı. Tekirdağ Ziraat Fakültesi Dergisi, 12 (1): 81-90.

Akat, H., G. Çetinkale Demirkan, Ö. Akat, B. Yağmur ve İ. Yokaş, 2015b. Arıtma çamuru uygulamalarının Limonium sinuatum 'Compindi White' çeşidinde bitki gelişimi, verim ve çiçek kalitesi üzerine etkileri. Ege Üniversitesi Ziraat Fakültesi Dergisi, 52 (1): 107-114.

Akat, H., G. Çetinkale Demirkan, İ. Yokaş, 2013. Atık çamurun 'Matthiola incana' yetiştiriciliğinde bitki gelişimi ve kalite üzerine etkisi. 5. Ulusal Katı Atık Yönetimi Kongresi, 29 Mayıs-1 Haziran 2013, Kocaeli sf: 508-520.

Bai, Y., C. Gu, T. Tao, X. Zhu, Y. Xu, Y. Shan and K. Feng, 2014. Responses of Ryegrass (Lolium perenne L.) grown in mudflats to sewage sludge amendment. Journal of Integrative Agriculture, 13 (2): 426-433.

Bose, S., A. Jain, V. Rai and A.L. Ramanathan, 2008. Chemical fractionation and translocation of heavy metals in Canna Indica L. grown on industrial waste amended soil. Jr. of Hazardous Materials, 160: 187-193.

Bramryd, T., 2013. Long-term effects of sewage sludge application on the heavy metal concentrations in Acid Pine (Pinus sylvestris L.) forests in a climatic gradient in Sweden. Forest Ecology and Management, 289:434-444. uygulamalarının yanısıra kontrol parsellerinde ikinci yıl ortaya çıkan birikimlerin de olması nedeniyle özellikle $\mathrm{Ni}$ ve $\mathrm{Pb}^{\prime}$ un araştırma alanı toprağında da bulunduğu düşünülmektedir.

Arıtma çamuru uygulamalarının tüm dozlarının Platanus orientalis türünde herhangi bir toksik etki meydana getirmeyerek, bitki gelişimini olumlu yönde etkilediği belirlenmiştir. Arıtma çamurlarının farklı alanlarda kullanılabileceği ancak kullanım dozları ayarlanarak bitki açısından toksik düzeylere çıkmasının engellenmesi gerekmektedir.

Arıtma çamurlarının süs bitkisi yetiştiriciliğinde saksı ortamı içerisinde Platanus orientalis türünün yetiştiriciliğinde de kullanılabileceği böylece atık bir materyalin yeniden kullanımının sağlanmasına imkan verebileceği düşünülmektedir. Ülke ekonomisine ve sürdürülebilirliğin sağlanmasına katkıda bulunarak önemli bir sorun olan arıtma çamuru bertarafında alternatif olabileceğini göstermektedir. Arıtma çamurlarının süs bitkisi sektöründe kullanımının çağdaş bir geri dönüşüm sistemi içerisinde çözümlenebileceği kanısına varılmıştır.

\section{TEŞEKKÜR}

ZF2011D29 no'lu projenin gerçekleştirilmesinde destek sağlayan Çukurova Üniversitesi Bilimsel Araştırma Projeleri Komisyonuna teşekkür ederiz.

Çelebi, Z.Ş., Ö. Arvas, R. Çelebi ve İ.H. Yılmaz, 2010. Atıksu arıtma çamuru ile tesis edilen yeşil alanda İngiliz Çimi (Lolium perenne L.)'nin performansının belirlenmesi. Tekirdağ Ziraat Fakültesi Dergisi 7 (3), 111-118.

Çelebi, Z.Ş., Ö. Arvas, R. Çelebi ve İ.H. Yılmaz, 2011. Rizomlu Kırmızı Yumak (Festuca rubra var. rubra) ile tesis edilen yeşil alanda atık su arıtma çamurunun tesis gübresi olarak değerlendirilmesi. Ekoloji, 20 (78):18-25.

Çetinkale Demirkan, G., H. Akat ve İ. Yokaş, 2014. Atık Su Arıtma Çamurunun Clarkia amoena (Yer Açelyası) Türünde Bitki Gelişimi ve Çiçeklenme Üzerine Etkisi. U.Ü. Ziraat Fakültesi Dergisi, 28 (2): 49-57.

Çetinkale Demirkan, G., H. Akat ve İ. Yokaş, 2013. Atık çamurun kapak malzemesi olarak kullanımının bazı çim türlerine etkisi. V. Süs Bitkileri Kongresi, 06-09 Mayıs 2013 Yalova.

Çimrin, M.K., M.A. Bozkurt ve İ. Erdal, 2000. Kentsel arıtma çamurunun tarımda fosfor kaynağı olarak kullanılması. Tarım Bilimleri Dergisi, 10 (1): 85-90.

Fuentes, D., B.K. Disante, A. Valdecantos, J. Cortına and V. Ramo'n vallejo, 2007. Response of Pinus halepensis Mill. Seedlings to biosolids enriched with $\mathrm{Cu}, \mathrm{Ni}$ And $\mathrm{Zn}$ in three mediterranean forest soils. Environmental Pollution, Volume 145: 316-323.

Garcia-Gomez, A., M.P. Bernal and A. Roig, 2002. Growth of ornamental plants in two composts prepared from agroindustrial wastes. Biores. Technol. 83, 81-87. 
Grigatti, M., M.E. Giorgiani and C. Ciavatta, 2007. Compost-based growing media: Influence on growth and nutrient use of bedding plants. Bioresource Technology, Volume 98 (18): 3526-3534.

Hernández-Apaolaza, L., A.M. Gascó, J.M. Gascó and F. Guerrero, 2005. Reuse of waste materials as growing media for ornamental plants. Bioresource Technology, Volume 96 (1): 125-131.

Isaac, A.R. and J.D. Kerber, 1969. Instrumental Methods for Analysis of Soil and Plant Tissue. Perkin Emler Crop. Atomic Absorption Dept. Norwalk.

Kabata-Pendias, A., 2011. Trace Elements in Soil and Plants. $4^{\text {th }}$ Edition, CRC Press, New York. ISBN: 978-1-4200-9368.

Kacar, B. ,1972. Bitki ve Topağın Kimyasal Analizleri. A.Ü.Z.F. Yayın 453.

Kacar, B. ve A. İnal, 2008. Bitki Analizleri. Nobel Yayın Dağıtım, Ankara.

Katkat, A.V. ve B.B. Aşık, 2010. Arıtma çamurlarının tarımsal amaçlı kullanımı ve gübre değeri. 5. Ulusal Bitki Besleme ve Gübre Kongresi, 15-17 Eylül 2010. İzmir.

Li, S., K. Zhang, S. Zhou, L. Zhang and Q. Chen, 2009. Use of dewatered municipal sludge on canna growth in pot experiments with a barren clay soil. Wate Management 29:1870-1876.
Manas, P. and E. Castro, 2008. Quality of Maritime Pine (Pinus pinaster Ait.) seedlings using waste materials as nursery growing media. J. New Forest, 37: 295-311.

Ostos, J.C., R: López-Garrido, J.M. Murillo and R. López, 2008. Substitution of peat for municipal solid waste and sewage sludge based composts in nursery growing media: effects on growth and nutrition of the native shrub Pistacia lentiscus L. Biosource Technology, 99:1793-1800.

Pathak, A., M.G. Dastidar and T.R. Sreekrishnan, 2009. Bioleaching of heavy metals from sewage sludge: a review. Journal of Environmental Management 90: 2343-2353.

Slawin, W., 1955. Atomic Absorbtion Spectroscopy Interscience Publishers New York-London Sydney.

Tüfekçi S., G. Gülbaba ve F. Tokgönül, 2008. Tarsus evsel arıtma çamurununn Okaliptüs ve Kızılçam fidanları üretiminde kullanılması. Çevre ve Orman Bakanlığı Yayın No: 368 ISBN: 978-605-393-042-6 DOA Yayın No: 49

Yıldız, S. ve M. Değirmenci, 2009. Sivas atık su arıtma tesisi arıtma çamuru bertarafi uygulamaları. II. Ulusal Arıtma Çamurları Sempozyumu, 04-06 Kasım, İzmir. 175-184 